\title{
BASES NARRATOLÓGICAS PARA UNA NUEVA LECTURA DE "EL INFIERNO TAN TEMIDO" DE ONETTI
}

\author{
POR \\ J. GUILLERMO RENART \\ University of Ottawa
}

\section{UNA OPCIÓN DE LECTURA}

En el centro de una lectura de "El infierno tan temido" (1957) — quizás el cuento de Onetti más valorado por la crítica ${ }^{1}$ - se opera una función semiósica de excepcional fuerza expresiva: el estatus del narrador, principalmente desde su carácter homodiegético, y en eficaz alianza con elementos convergentes del texto, genera una poderosa impresión de realidad en el significado y su referente; ${ }^{2}$ así la historia - cuyos sucesos y personajes se instalan enteramente en el ámbito de lo mimético-y la problemática vital que la historia ejemplifica, rezuman, en tal lectura, intensa y honda realidad. La impresión no se neutraliza ni disminuye en las aseveraciones de este narrador homodiegético que suponen un acceso cognicionalmente ${ }^{3}$ privilegiado a la mente de los

${ }_{1}$ Para la crítica del cuento que he empleado en este trabajo (y, más aún, en el del comentario textual que lo complementa y continua: cf. abajo, "Una tarea doble"), véase la lista de "Obras citadas".

${ }^{2}$ Para la terminología narratologica empleada, comprendiendo expresiones como "estatus" del narrador, "postura ideologica", "postura psíquica", "postura perceptual", etc., sigo principalmente a Lanser (1981), y a Genette (1972 y 1983); cf. también Prince (1987), y Reisy Lopes (1987). He decidido hablar de "impresion" versus "ilusion" de realidad a pesar de que el "significado" o referente interno del texto (la historia) sea ficcional, para evitar posibles sospechas de un inmanentismo en la concepción epistemologica del texto literario que estoy lejos de compartir. Por otra parte, considero aqui tanto la ficcionalidad como la realidad en su dimensión semísica: como códigos de la mente humana (Renart 1989: 389); la "impresion" de realidad se puede dar en los objetos de ambos códigos, aunque, por cierto, esa impresión sea sólo una "jlusión" en los objetos del código ficcional -la historia, en este caso. Siguien do un uso cada vez más extendido, opongo "semiosis" (la significación, su estructura y funcionamiento) y derivados ("semiósico", etc.), a "semiótica" (la reflexión sobre la semiosis) y derivados.

${ }^{3}$ El uso del su fijo - al en "cognicional" y derivados ("cognicionalmente", etc.) -en lugar, en este caso, de -ivo ("cognoscitivo")-responde a una norma general que continúo adoptando en este trabajo, ya seguida en trabajos míos anteriores, cuya finalidad es evitar las significaciones no "neutrales" de los otros usos. Así también, con respecto a "imaginal" por 
personajes, pues no se produce la paralepsis que comúnmente ocurriría. La implícita solución a la paralepsis que la lectura asume, no parece ser otra que la prolongación de la impresión de realidad en la presuposición ideológica de que el narrador tiene la autoridad cognicional necesaria para hacer tal clase de aseveraciones - tiene, pues, privilegio cognicional ideológico, aunque no perceptual. De ese modo se cierra el círculo estético en apropiada circularidad semiósica, pues es la impresión de realidad —extendida y transferida ahora en elemento de la postura ideológica del texto-la que contribuye a la construcción semiósica del estatus del narrador, específicamente a su aspecto más relevante en este proceso, su carácter homodiegético. Y es ella también, y por la misma razón, el factor principal de que el texto de Onetti logre una solución admirable al viejo problema de la incompatibilidad entre las propiedades específicas de la homodiégesis del narrador y las de la heterodiégesis. En este proceso no es, obviamente, el solo narrador el agente de la impresión de realidad y el sujeto de la postura ideológica presupuesta. Siendo narrador público, y estando dotado de privilegio cognicional, honestidad, credibilidad y competencia, parecería aceptable el no concebirlo como ónticamente distinto del autor implícito, sino uno y el mismo con él (Lanser 1981: 151-152, 169-172), por lo cual dicho agente y sujeto sería, en verdad, el narrador-autor implícito. Por su parte el lector implícito, que reconoce en el narrador estos atributos y asume la impresión de realidad y su extensión ideológica, resulta co-productor de tal impresión y sujeto partícipe de tal postura.

\section{LA IMPRESIÓN DE REALIDAD PARA EL LECTOR IMPLICITO}

Me incumbe explicar enseguida los supuestos de la síntesis precedente, pero quizás convenga que le proceda la consideración del nivel "superficial" de tal lectura —el de la historia - porque es esa historia (parte del significado, o referente interno) la portadora primaria de la impresión de realidad, y, al contextualizarse como paradigma metonímico de un referente (o referente externo), responsable de que esa impresión se propague al mismo: a la problemática humana que ella actualiza ejemplarmente.

Se trata de la misma historia, que seguramente han compartido tantos lectores del cuento, la que Mario Benedetti ha resumido cabalmente de esta manera:

oposición a "imaginativo" (que supone personificacion) o a "imaginario" (que denota irrealidad), como lo señalé en Renart (1989): 421, n. 6; análogamente con respecto a “discursal", "expresional", "figuracional", todos con sendas formas en -ivo, sugestivas de una acción o valoración ausentes de la simple mención del hecho neutro; "historial", perteneciente a la "historia", poroposición a "relato"), diferente de "diegetico" (perteneciente a la diégesis, el mundo narrativo entero que la historia evoca metonímica y sinecdóquicamente: Genette 1983: 13; "contentual", de uso más general y extendido (Renart 1982). 


\begin{abstract}
Risso, el protagonista, se ha separado de su mujer, a consecuencia de una infidelidad de extraño corte (ella se acostó con otro, pero sólo como una manera de agregar algo a su amor por Risso). La mujer desaparece, y al poco tiempo empieza a enviar (a él, y a personas con él relacionadas) fotos obscenas que, incréblemente, van documentando su propia degradación. Risso llega a interpretar (y ella misma pretende hacer, podemos agregar) esa agresiva publicidad, ese calculado desparramo de la impudicia, como una ins6lita, desesperada prueba de amor. Y quizá (pese al testimonio de alguien que narra en tercera persona y adjetiva violentamente contra la mujer) tuviera razón. Lo cierto es que el último envio acierta "en lo que Risso tenía de veras de vulnerable"; acierta en el preciso instante en que el hombre habia resuelto volver con ella (Benedetti 1981: 138-139).
\end{abstract}

Para la lectura, pues, que aquí nos ocupa, (para el lector implícito de tal lectura) esa historia representaría de manera ejemplar y con la intensa impresión de realidad aludida una trágica y desgarradora ${ }^{4}$ problemática vital: esa radical necesidad de amor tan común entre los seres humanos. Esa imposibilidad de su realización a causa de ataques desesperados entre las personas que se aman, significativos de algo bien distinto de lo que parecen, y provocadores de incomprensiones fatales para las relaciones y los individuos involucrados. Pero la impresión de realidad estaría ya, y con toda fuerza, en la historia misma, incluso en sus partes "increíbles" o "extrañas": las dos inusuales acciones de Gracia - su relación sexual con otro hombre para enriquecer su amor a Risso, y el envío de las fotografías como desesperado acto de amor al mismo Risso-, y la heroica comprensión afectiva y moral de éste. Todo esto podrá ser superficialmente extraño, pero no menos es fruto de unas motivaciones y aspiraciones profundamente reales para cierto nivel psíquico e ideológico del lector implícito. Tal lector estaría respondiendo al texto con una tácita aserción de esta suerte: “ Ésa es la realidad: Asi ocurrió y debia ocurrir porque responde, en parte, a la realidad de 'nuestra' común condición humana - la que compartimos esos actores y yo y todos los seres humanos-y en parte, a la realidad de 'nuestra' condición cultural - la de ellos y la mía." (La proporción de la atribución a la una o a la otra realidad depende obviamente de los presupuestos filosóficos -o bien cultos, o bien de sabiduría popular, etc.que profese el individuo concreto que encarne al lector implícito en cada instancia de lectura).

No sólo, pues, las acciones, tomadas aisladamente, rezuman en tal lectura completa realidad; también lo hacen los actores de la historia, los personajes, incluidoel homodiegético narrador. Yesto, principalmente, porque el lector que

\footnotetext{
4 Tomo y adapto el último adjetivo de Emir Rodriguez Monegal, que lo refiere a este relato considerado en conjunto $(1966,226)$; para una aplicacion más plena de esta idea, ver en la conclusion de este trabajo citas y comentarios de ciertas observaciones esenciales de Rodríguez Monegal sobre los cuentos de Onetti.
} 
asume en sí al lector implícito siente entre ellos y nosotros ${ }^{5}$ una perfecta cercanía óntica, psíquica, incluso moral (en formas diferentes con los diversos personajes), y aún cultural (en grados distintos para distintos lectores). En particular, al narrador-autor implícito no lo siente como un ser ajeno a la humanidad porque no participara en la historia como personaje y por su (verdadera o aparente) posesión de propiedades extranaturales, como sería un privilegio cognicional inalcanzable por el ser humano. Lo siente como una representación de nuestra mentalidad y nuestra cultura -así como de la mentalidad y la cultura de sus personajes-, que participa como testigo, óntica, psíquica y moralmente compenetrado al máximo con la historia que cuenta, con su tragedia y su problemática. Resulta así la voz de nuestra realidad: de nuestro pensar, sentir y querer. Por ello, para tal lector, los dos personajes protagonistas merecerán plenamente la empatia que el narrador muestra con ellos (en grados diferentes: con Risso más que con Gracia), pues es expresión exacta de la suya. Una empatía afectuosa porque valora a esos seres, y porque es comprensiva de los errores que ellos cometen a causa de las insatisfacciones profundas que compartirian con los demás seres humanos como proyección viviente de una parte humana esencial. Y a la vez que esta honda empatía hacia los sujetos mismos, sus actos, sin embargo, merecen para el lector implícito una evaluación positiva o negativa según sean aceptables o condenables por una moral que, para él, todos compartiríamos o deberíamos compartir, y a la que, por tanto, también ellos deberian someterse.

Al final parecerá ocurrir una repentina claudicación en un aspecto de esta postura global. El elemento ideológico pesimista, que suele a última hora en la obra de Onetti reprimir toda consideración positiva de la vida humana y el universo, de alguna manera se inmiscuirá mediante una visión vulgar de las

${ }^{5}$ Acabo de escribir/nosotros/sin comillas, y así lo seguiré haciendo casi siempre desde aquí, lo mismo que/nuestro -a/, pero ya sabemos que se refieren, en parte a la comunidad cultural, y en parte a la común condición humana, presupuestas por el lector implícito de la lectura a que me vengo refiriendo. Nótese tambiên que me he de referir en seguida a la cercanía cultural entre los personajes y el lector implicito, y más adelante a la cercanía cultural entre los personajes y el narrador. Naturalmente el concepto se toma en un sentido más genérico en el primer caso que en el segundo. En éste la cercanía cultural es la de dos seres humanos que comparten la misma lengua, país, grupo social, amistad o conocimiento mutuo, afecto (posiblemente recíproco), etc. Ninguno de estos elementos es necesario en el primer caso; se trata entonces esencialmente de comunidad ideologica y axiológica, y subordinadamente de una comunidad más vaga, de carácter vital (donde pueden intervenir factores de tiempo, espacio, organización social, actividad laboral, intereses intelectuales y/o artisticos, preocupaciones existenciales, etc.) que nos hace sentir a alguien suficientemente cerca como para considerarlo miembro de la misma unidad cultural. En este sentido puede alguien de nuestros días sentirse partícipe, con Aristóteles o Pericles, de la misma cultura greco-latina-occidental, o con Unamuno, T. S. Eliot, y Borges, de la misma cultura occidental moderna. 
acciones del tipo de las que Gracia lleva a cabo. Esta visión es representada por un momento de Lanza, que tiene a su cargo la clausura del cuento. El repentino contraste entre las dos visiones, las dos posturas, puede percibirlos el lector como una contradicción lógica con la del narrador-autor implícito/lector implícito (con la "nuestra"). Pero puede también concebirlo como la representación de un conflicto psíquico e ideológico interior al mismoactor, que comparte parcialmente la segunda visión, como si fuera, nuevamente, proyección viviente de una realidad nuestra esencial también: un conflicto entre una postura perteneciente a una parte más noble, o más esperanzada, de nuestro ser, y una postura propia de una parte inferior, o más escéptica o desilusionada, del mismo. Pero si las dos son parte del mismo ser pensante y sentiente, parecen, en definitiva, ser parte de una misma postura global, en la cual predominará la parte superior, aunque no dejará de llevar en sí el desgarramiento de la contradicción. Essta es la justificación semiósica de tal final abrupto — y es la consumación de la lectura que nos ocupa.

\section{LA IMPRESIÓN DE REALIDAD, EL ESTATUS DEL NARRADOR Y LA RED SEMIÓSICA}

Si nuestra propia lectura puede compartir el componente contentual de la lectura que nos atañe, delineado hasta aquí, podremos quizá compartir también, en el nivel expresional de la lectura, el reconocimiento de un mismo conjunto convergente de factores semiósicos de aquel contenido. (Como era de esperar, a causa de la característica activación significante del texto estético en todos sus niveles, parte de estos factores está comprendida en el contenido mismo, lo cual resultará evidente a continuación; (Eco 1979: 270-273; 1962: 160-170). Me refiero a ciertos aspectos del estatus del narrador, y a su alianza semiósica con otros componentes expresionales para la obtención del mismo efecto semántico.

Entre los aspectos del estatus del narrador, el más fundamental es su carácter homodiegético, que (en primero y primario lugar) lo acerca a los personajes ónticamente. A éste se agregan unos aspectos que son en sí mismos de postura, pero que también configuran el estatus del narrador si se entiende su ámbito expandido hasta abarcar aquellos elementos de otras dimensiones que determinan su rasgo constitutivo fundamental. Si éste es la homodiégesis en el cuento de Onetti, la homodiégesis particular de este narrador, su índole homodiegética, se caracteriza por la cercanía psíquica -principalmente afectiva-e ideológica a los personajes, sobre todo a Risso. Se impregna esta última de cercanía moral, i. e., de una aprobación (crítica y restringida, pero profunda y sincera) de sus conductas, brotada de una atención máximamente lúcida y una radical preocupación y compromiso moral por sus personas y por la problemática humana que representan. Al unirse estos rasgos con la pertenencia del narrador homodiegético al mismo grupo social de amistades de Rissoy Gracia, se origina asimismo una fuerte cercanía cultural. La homodiégesis se encuentra, así, en el origen de la cercanía óntica y cultural del narrador al 
personaje, y es un factor fuertemente corroborador de su cercanía ideológicomoral y afectiva - a más de informacional, como en seguida diré. Esta íntima cercanía, al ser compartida por el lector implícito, se hace el factor principal de la impresión de realidad. Los componentes expresionales que forman la antedicha alianza semiósica con el estatus del narrador son, ante todo, los aspectos mismos de la postura psíquica que acabo de indicar y (otro aspecto de la misma) la cercanía informacional; a ellos se agregan principalmente el estilo (en su sentido amplio: conjunto de rasgos característicos y/o semiósicamente relevantes de cierto uso de la lengua en el discurso) del discurso del narrador, el estilo indirectolibre, lo que he de llamar paralepsis estilística, y la abundancia de la determinación gramatical en ciertos lugares estratégicos. Incluso la peculiar clausura del cuento (señalada en el apartado anterior), un componente que aparentemente sería incompatible con esta red semiósica pues parece romper la coherencia de postura ideológica que esta alianza semiósica contribuye a construir, resulta, dentro la lectura propuesta, un factor coadyuvante.

Pero hay un obstáculo para la realización del aspecto más fundamental la homodiégesis del narrador- de esta red semiósica; es la aparente escisión, en algunas partes del cuento, entre el narrador homodiegético, que según la convención más habitual carecería de privilegio cognicional, y un narrador heterodiegético, dotado de privilegio cognicional. Esto resulta más notorio porque el lector que aborda "El infierno" por primera vez cree encontrarse (al principio del cuento) con un narrador heterodiegético, cognicionalmenle privilegiado; sólo tras llegar en su lectura a la segunda de las siete secciones en que se divide tipográficamente el texto, aparece la homodiégesis en el narrador. Unicamente entonces puede surgir en el lector la postulación de la unicidad del narrador. Pero si conviene en que existe tal unicidad, convendrá también en que el texto de Onetti constituye el memorable replanteo y solución, ya anunciados, del antiguo problema de la incompatibilidad entre, por una parte, la homodiégesis del narrador y sus propiedades semánticas específicas, y, por otra parte, la heterodiégesis del narradory sus propiedades semánticas especificas - pudiendo resumirse las del primero en una superior capacidad para expresar la perspectiva subjetiva del personaje narrador, y las del segundo en su superior capacidad para la expresión de una perspectiva objetiva de los personajes, los sucesos y, en general, el mundo representado (Genette 1972: 258). El texto de Onetti ofrece, en efecto, una clase de fusión notablemente eficaz de ambas modalidades.

Ciertamente la posibilidad de alguna clase de fusión entre las dos modalidades ha sido considerada en la narratologia moderna (Genette 1983: 71-72, Stanzel 1986: 99-110); el texto de Onetti -de aceptarse la lectura que viene motivando estas reflexiones- conseguiría la fusión a partir de la homodiégesis del narrador, alcanzando una solución de lograda eficacia artística a las paralepsis que, con un narrador homodiegético, se plantearian. Resolverlo es indispensable para que no disminuya o se acabe la impresión de realidad y la consiguiente eficacia estética. Ya sabemos que tal solución, la más coherente dentro de esa lectura, concebiría el privilegio cognicional manifestado, como 
ideológico y no perceptual; el narrador no "vería" (no percibiría) el interior de los personajes - pues se trataría de un narrador homodiegético sin tal clase de privilegio-, pero sabría con toda certeza lo que ocurre basado en una parte absolutamente firme de su postura ideológica. Por postura ideológica entiendo (integrando la denominación sugerida por Lanser y una definición de Fowler) la actitud de un actor textual con respecto a la historia que vive y/o relata, y al mundo evocado por la misma, conforme al "sistema de creencias, valores y categorías según el cual ... entiende el mundo" (Fowler 1986: 130, traducción mía; Lanser 1981; ver también Booth 1983: 419); quizás convenga advertir con el propio Fowler que la ideología está así lejos de significar necesariamente "falsa imaginación", error, o cualquiera de los sentidos menoscabadores del vocablo.

Ahora bien, he dicho en el apartado precedente que el lector implícito se explica las acciones relatadas como consecuencia natural de la condición de sus sujetos. Loque así está haciendo es extender la impresión (empírica) de realidad de tales acciones, a juicio ontológico sobre dicha condición ("así debe ocurrir porque es parte de nuestra condición"); esto es particularmente evidente cuando se trata de acciones cuyo conocimiento presupone privilegio cognicional por parte del narrador. Tal extensión es parte de una postura ideológica. Extiende, en efecto, la particularidad empírica a ley que la trasciende, y que permite deducir y predecir acciones - incluso aseverar con certeza su ocurrenciabasándose en una supuesta regularidad empíricamente indemostrable. Estamos, pues, en el terreno de la "creencia" - como también en el de las "categorías" y los "valores" - conforme a los cuales es entendido el mundo. Basado en ellos, el lector implícito piensa que el narrador-autor implícito habla con toda autoridad diegética (Lanser 1981: 172); se trata, pues, de una postura ideológica total, i.e. del texto/de la lectura.

Pero nótese que las creencias no parecerían poder activarse y alcanzar la fuerza necesaria para que se diera este proceso, sin que al mismo tiempo la impresión de realidad de lo narrado lograra la enorme fuerza que consigue. El resultado es tan exitoso que cuando desaparecen los signos inequívocos de la homodiégesis (factor clave de esta impresión, como sabemos) no hay obstáculo para seguir atribuyendo al narrador tal carácter, como no lo habra antes para atribuírselo retroactivamente desde antes que esos signos aparecieran. Tampoco lo hay, incluso, para que las paralepsis que, al parecer, se plantean en ambas vertientes temporales de la lectura, se interpreten sin esfuerzo como expresión natural de la autoridad diegética del narrador. Estamos, así, ante el caso, antes aludido, de la circularidad semiósica de lo estético, generalmente asociada a su autorreflexividad semiósica (Eco 1979: 270-273; 1972: 160-170). Lo que en un momento ha sido factor, se convierte en efecto, y viceversa; más aún, ambas funciones pueden coexistir simultáneamente en el mismo segmento del texto. (Y la misma circularidad se constata al advertir que el privilegio cognicional del narrador homodiegético no sólo queda legitimado como efecto de la impresión de realidad, sino que también - por la mayor autoridad que con ese privilegio 
el narrador entraña e irradia - es factor de la misma.) Es importante advertir aquí que la posible contribución de cualquier otra solución a la paralepsis debería cumplir el mismo requisito para la preservación de la integridad de esta lectura: preservar en su plenitud la impresión de realidad. Al considerar la viabilidad de otras soluciones (en el artículo de explication: ver apartado que aquí sigue), ése, por consiguiente, deberá ser el criterio principal para decidir cuán compatibles e integrables serán tales soluciones con la propuesta.

\section{UNA TAREA DOBLE}

Las observaciones precedentes sugieren la necesidad de una tarea doble. He señalado la existencia de una red semiósica nucleada en la homodiégesis del narrador, cuyo significado global era la impresión de realidad. He señalado luego un obstáculo para la viabilidad del núcleo de la red (la homodiégesis) consistente en la aparente escisión de la voz narrativa en dos emisores, uno de ellos heterodiegético. El signo de tal escisión aparente era el privilegio cognicional, que exige un narrador heterodiegético $\longrightarrow$ bien, al atribuirse a narradores homodiegéticos, origina paralepsis que requieren una solución para no neutralizar la impresión de realidad y la consiguiente eficacia estética. Hemos visto que nuestra lectura mantenía decididamente la homodiégesis, aplicando una solución semiósicamente circular a la paralepsis, generada por la impresión de realidad. Debo ahora notar que la misma red semiósica que se nuclea en la homodiégesis para generar (anteriormente: con prioridad semiósica) esa impresión de realidad, constituye también un segundo factor principal o, más bien, un segundo conjunto principal de factores de la permanencia de la homodiégesis en las partes del cuento en que parece producirse la escisión -0 de la generación retroactiva de la misma en la primera sección del texto. Y este efecto se produce por la misma razón - la cercanía, que la red genera, del narrador al personaje, constituyente esencial de la impresión de realidad. Examinar el funcionamiento de esa red, por tanto, es estudiar la producción de ambas significaciones: la impresión de realidad, y la homodiégesis del narrador. Como la primera significación no se cuestiona, pero sí la segunda, parecería que la atención debiera enfocarse en el estudio de la red semiósica en cuanto significante de la homodiégesis - y en ello quedaría implicado el examen de su contribución a la impresión de realidad.

La indagación así delineada imponía una tarea doble, predominantemente teórica la primera, de neta aplicación práctica la segunda. La necesidad de la primera se me impuso al empezar el trabajo (en un primer ensayo) con la tarea de la segunda. En efecto, la mayoría de los componentes textuales de tal red pueden denominarse con términos propuestos por la narratología que principalmente arranca en Henry James, según son expresados, desarrollados y complementados sobre todo por Genette (1972 y 1983), Vitoux (1982) y Susan Lanser (1981), y es principalmente de esta línea narratológica que he de tomar la mayoría de los conceptos que considero pertinentes aqui. Sin embargo, 
encontré necesario realizar previamente tres cosas. Una fue la aclaración de varios términos, impuesta por el hecho de que la narratología es una disciplina en formación y terminológicamente dispersa e inestable. Otra, tener efectivamente en cuenta que a los términos conocidos se debían sumar dos o tres cuya denominación -la delimitación terminológica del componente-, o cuya concepción misma en algún aspecto o caso particular, es de mi propia cosecha; he propuesto algunas de estas ideas en otros lugares (Renart 1987), pero la importancia de su uso en la presente lectura del texto de Onetti requería hacerlo aquí de manera más formalizada. En tercer lugar, como varios de estos componentes textuales tienen entre sí una relación lógica--de género a especie, de un elemento a sus clases, o de un elemento a sus propios componentes, etc.la claridad expositiva imponía una exposición orgánica de los mismos; sólo así podía fundamentarse y explicarse claramente la lectura propuesta. Por todo ello, dicha exposición constituirá el resto del trabajo. (La segunda tarea -una explication que haga la aplicación detallada de esas ideas a partes del texto especialmente relevantes, figurará en una publicación próxima, Renart 1992.) Sólo con la tarea que ahora sigue quedará completa la propuesta de las bases narratológicas para la lectura que he sugerido, que ha de consistir, en realidad, en la descripción de la red semiósica propiamente dicha.

LA RED SEMIOSICA SIGNIFICANTE DE LA IMPRESIÓN DE REALIDAD EN "EL INFIERNO TAN TEMIDO"

(A) Estatus del narrador, y relación de la información que el propio narrador da con la información que él mismo posee.

Partiré de la observación de un hecho de postura psíquica que se da en el cuento, especificamente de postura perceptual y (digamos) "informacional" (Lanser 1981, 201-202): En los pasajes en los que el narrador, ejerciendo (actualmente) privilegio cognicional, opera con focalización interna en los personajes (Risso y/o Gracia), se sujeta casi siempre a dar sobre éstos la misma información que ellos poseen - $\mathrm{N}=\mathrm{P}$ si lo expresamos con el símbolo corriente (Genette 1972, 206). Pero ya sabemos que, siendo un narrador homodiegético mimético, el ejercicio de la focalización interna supone la aplicación de una solución a la paralepsis para que el cuento no transgreda sus convenciones básicas y se mantenga la impresión de realidad. Nótese que presupongo $-\mathrm{y}$ propongo- así una distinción nítida entre, por una parte, la focalización, y, por otra parte, tanto la relación entre la información dada por el narrador y la poserda por el personaje, como (nótese bien) entre la información dada por el narrador y la poseída por el mismo narrador.

Esta diferenciación quiere ser una consecuencia de la importante distinción que Genette postula entre loque llama-de manera "evidemment métaphorique" $(1983,28)$ - modo y voz, y que prefiero denominar con Susan Lanser - de manera quizás menos metafórica, y posiblemente más fundamentada en la reflexión semiótico-narratológica-postura y estatus del narrador (Lanser 198, 
85-107). Mi antedicha diferenciación quiere también mantener, y delimitar con más precisión, una distinción entre focalización e información que se da en la misma obra de Lanser (Lanser, 202-211). Destaco que hablo de diferenciación o distinción, no de separación recíprocamente exclusiva, de los conceptos, pues veremos que la información es el género dentro del cual quedan comprendidas - según criterios diferentes - las especies o clases de información antedichas, incluso la focalización como una más de tales especies o clases.

Detengámonos, pues, un momento, en la relación entre la información que el narrador da y la que él mismo posee. La información que un narrador da sobre el objeto de su discurso puede ser toda la información - pertinente al momento diegético o historial relatado— que él posea, puede ser menor, y también puede ser mayor. En los dos primeros casos la comunicación de información no afecta la naturaleza de su estatus semiósico-narrativo (o "voz" en terminología de Genette), aunque pueda contribuir a definir la índole de ese estatus: su "personalidad" como narrador. Pero si da una información mayor de la que posee o a la cual pueda tener acceso (sin querer mentir) comete una infracción contra su convencional naturaleza o identidad; el fenómeno de postura afecta a su estatus mismo. Y esto vale tanto para el narrador básico como para cualquier personaje que asuma temporalmente la función narrativa. En ambas situaciones, pues, podrán considerarse y aplicarse a estos fenómenos las relaciones de los tres casos propuestos por Pouillon-Todorov-Genette (Genette 1972, 206), y expresarse éstas simbólicamente así: $\mathrm{N}<\mathrm{N}, \mathrm{N}=\mathrm{N}, \mathrm{N}>\mathrm{N}$, donde $\mathrm{N}$ simboliza el narrador. Es en el primer caso cuando ocurre la paralepsis (Genette, 93-211); y es en el tercero cuando se da una paralepsis (Genette, 211-212); como he dicho, la paralepsis tiene importancia mayor en nuestra lectura.

Quisiera destacar que los fenómenos de postura recién aludidos, concernientes a la relación de la información que el narrador da con la que posee un personaje $(\mathrm{N}<\mathrm{P}, \mathrm{N}=\mathrm{P}, \mathrm{N}>\mathrm{P})$-concebidos por Genette, a diferencia de lo que propondré enseguida, como clases de focalización (Genette 1971, 206-207) también pueden afectar la naturaleza del estatus. Ocurre esto si caen dentro del caso $N>N$,i.e., si lainformación que el narrador proporciona es mayor que la que posee o le es alcanzable. Y nótese bien que ello puede ocurrir en los tres casos

\footnotetext{
${ }^{6}$ La distinción entre, por una parte, información que el narrador da con respecto a la que el personaje posee, y, por otra parte, focalización, está implícita en Renart (1987), aunque en letra impresa no la he propuesto antes explícita y formalmente. Me impulsa a hacerlo, por una parte, su prolongada aplicación exitosa en el análisis de textos en mis cursos postgraduados de narratologia en la Universidad de Ottawa -así como en seminarios del mismo nivel y materia dados, como profesor invitado, en la Universidad de la República, Montevideo, y la Universidad Católica de la misma ciudad-, y, por otra parte, la necesidad (imperiosa, creo yo) de tal distinción para poder describir y explicar adecuadamente numerosas situaciones narrativas - de las cuales unas pocas (aunque de gran relevancia semiósica en este cuento) aparecen en el análisis del artículo de comentario textual que continúa y complementa al presente.
} 
que aquí nos concierne, incluso en el de $\mathrm{N}<\mathrm{P}$. Así, por ejemplo, el personaje cognicionalmente limitado-que asume la narración en determinado momento y aventura decir, sin pensar que tenga ninguna justificación empírica, inferencial o testimonial para ello, que Juan está empezando a interesarse afectivamente por María y que dentro de cierto tiempo acabará enamorándose ... cuando en la realidad Juan ya está completamente enamorado, parece estar excediendo sus límites cognicionales aunque dé una información menor que la que el personaje aludido (Juan) posee. Está, por consiguiente, cometiendo una infracción contra su estatus convencional en el relato. También este triple conjunto de fenómenos constituye una de las especies o clases del genérico fenómeno informacional que tiene notable relevancia semiósica en nuestra lectura del cuento.

(B) Tres soluciones a la paralepsis: En el apartado precedente destaqué la naturaleza específicamente informacional del fenómeno que Genette ha llamado paralepsis (1972: 211-212). Más arriba señalé que en "El infierno" la paralepsis constituye el obstáculo mayor para la clase y efectos semánticos de la homodiégesis del narrador que se da en la lectura practicada del cuento, y la solución operante en tal lectura constituiría un notable logro narrativo. Es necesario situar ahora esta solución en el contexto de otras soluciones que (en el trabajo de comentario textual deberán confrontarse con ella, para decidir cuán compatibles y cuán integradas [o no] con ella han de resultar). Es necesario también considerar el fundamento de su capacidad "naturalizadora" pues allí reside su capacidad "solucionadora".

Dos maneras bien conocidas como los lectores naturalizan $-\mathrm{y}$ así solucionan-este fenómeno son las siguientes: La primera es la "concesión": "concesión de la paralepsis por semejanza diegética". El lector "concede" al narrador el uso de la paralepsis como expresión o efecto de la certeza (u opinión) del propio narrador acerca de la semejanza entre el suceso relatado y el que supuestamente haya ocurrido en la realidad ficcional o diégesis, conforme a la información disponible. En este caso, ni el narrador ni el lector pretenden que la relación entre lo narrado y la supuesta realidad ficcional sea más que analógica $o$, si se prefiere, metafórico-metonímica: metafórica, en cuanto sustitución analógica del objeto "real"; metonímica, porque las entidades sustituyentes (personajes, acciones, objetos) son de la misma naturaleza que las sustituidas -0 , si se prefiere, de la misma especie: en este sentido comparten el mismo todo (son partes pro partibus). En esto radica la diferencia de la relación que se da en la metáfora que podría llamarse "alegórica”, i.e., entre entidades de naturaleza o especie diferente, como un diente y una perla, un cabello rubio y un trozo de oro. En cuanto historia ficcional, la misma relación metafórico-metonímica se encuentra entre ella y la realidad, pues remite a componentes de la realidad que tienen con los de la historia esa misma clase de

${ }^{7}$ Empleo el concepto de naturalización propuesto por Culler (1975): 134; ver también Rimmon-Kenan (1983), 142, n. 5. 
relación: son también - posibles - seres humanos, acciones humanas, objetos materiales. Como se ve, esta solución es doblemente tropológica: se observa en ella la relación metafórico-metonímica en una dimensión intratextual, y en una dimensión extratextual.

De estas dos concreciones tropológicas, es sólo la metafórico-metonímica en su dimensión extratextual la que se da en la segunda solución a la paralepsis, también muy conocida. Esta segunda solución podría llamarse la "negación": "negación de la paralepsis por inexistencia diegética"; considera que en verdad no existe paralepsis, pues todas las instancias de (aparente) ejercicio de privilegio cognicional por parte del narrador tendrían como contenido diegético conocimientos perfectamente accesibles por inferencia racional o por testimonio fidedigno - del propio sujeto, o de personajes que recibieron de él el testimonio apropiado o tuvieron medios para realizar las inferencias adecuadas. Se trata de la clase de asentimiento que hacemos al discurso de los historiadores, cronistas, periodistas, cuando aceptamos sin dudar aseveraciones suyas que trascienden el ámbito de su conocer directo (e.g. "Ese día Napoleón se levantó rumiando pensamientos de cólera"). Como se ve, de las dos concreciones tropológicas antedichas, se disuelve aquí la primera, y sólo permanece la segunda.

Pero hay una tercera solución a la paralepsis, que quizás haya sido considerada implícitamente muchas veces por críticos de la narrativa, aunque no sea moneda corriente en la narratología; es la solución que la lectura de "El infierno" que he sugerido asume como la más apropiada. En cotejo con las dos anteriores, podría llamarse la "superación ideológica": "superación de la paralepsis por imposibilidad ideológica". Como sabemos, consiste en postular que las instancias de privilegio cognicional del narrador tienen como principal origen y como apropiada justificación gnoseológica la postura ideológica que él asume.

Más precisamente: siguiendo una convención habitual de lectura de la narrativa ficcional, el lector implícito considera que la historia es expresión metonímica de cierta postura ideológica del narrador, de la cual tal lector participa: Postura ideológica, como he señalado, en sentido amplio, abarcadora de cierta concepción del mundo presentado, de sus actores, y de la vida de éstos, que va más allá de lo puramente comprobable con medios empíricos. Considera también que este mundo, vida y seres son expresión simbólico-analógica y sinecdóquica -i.e., por semejanza, y por proyección de parte hacia el todo- del mundo que concibe como real. Hasta aquí no se aparta de la aplicación de convenciones generales en la lectura ficcional. La peculiaridad surge cuando considera asimismo que tal postura ideológica permite a un narrador homodiegético mimético hacer aseveraciones que presuponen privilegio cognicional: que no son empíricamente comprobables ni se fundamentan en testimonios fidedignos. Obsérvese que, de las dos concreciones tropológicas señaladas para la primera solución, no se da aquí la modalidad metafóricometonímica en su dimensión intratextual (como para dicha solución), sino sólo 
en su dimensión extratextual (como para la segunda solución), a saber, la identidad de naturaleza o especie entre los componentes de la historia (seres o acciones humanos, objetos, etc.) y los de la realidad.

Una mirada atenta parece revelarnos que las tres soluciones son mímesis de situaciones de la vida real -de lo que codificamos vida real en nuestra semiótica diaria-; esta consideración puede ayudarnos a entender mejor su capacidad "naturalizadora". Las dos primeras soluciones miman dos clases de situacioncs (conversaciones; monólogos odiálogos mentales, etc.) en que hacemos aseveraciones basadas primariamente en inferencias oen testimonios fidedignos - basadas, pues, en el conocimiento empírico del mundo. En la primera clase de situaciones, correspondiente a la primera solución, la aseveración se considera probable; en la segunda clase, correspondiente a la segunda solución, la aseveración se considera cierta.

La tercera solución, en cambio, mima la clase de situaciones en que el saber empírico tiene una importancia secundaria, y es el saber ideológico el que principalmente fundamenta las aseveraciones. En la vida ordinaria presenciamos, compartimos o protagonizamos diariamente numerosos casos de esta clase. Cubren toda la gama de la moralidad humana. Algunos se hallan en los grados más bajos y pobres: e.g., los juicios -apodícticos para quien los guarda para sí o los verbaliza - basados puramente en prejuicios raciales, étnicos, de clase, de mentalidad cultural, etc. según los cuales los individuos o grupos involucrados tienen que obrar o haber obrado, sentir o haber sentido, pensar o haber pensado - de cierta manera, y no de otra. Otros se hallan en los casos más altos; así las certezas sobre lo que individuos o grupos hicieron, hacen o harán, exterior y/o interiormente, que se basan en sofisticados sistemas ideológicos, o elevadas concepciones óntico-morales de la condición humana. En suma, la posturaideológica del narrador era, por cierto, un factor semiósicamente relevante de su certeza u opinión en las dos primeras soluciones a la paralepsis (¿en que operación mental humana no es más o menos relevante la ideología?), pero no era el factor principal. Éste era la coherencia diegética según un modelo de probabilidad primariamente óntico-empírico-ynoun modelode probabilidad primariamente óntico-ideológico como en esta tercera solución.

(C) La paralepsis estilística. Propongo considerar como forma de paralepsis un fenómeno diferente, que tiene relevancia en la red semiósica a causa de su contribución a la unicidad del narrador por vía del acercamiento psíquico del narrador inicial al personaje — más bien, del personaje, Risso, al narrador, como en seguida veremos; es lo que llamaré paralepsis estilística. Aunque el nombre sea nuevo, el concepto mismo puede hallarse en la crítica de la narrativa. Si paralepsis es narración de elementos de la historia inaccesibles al emisor - narrador básico, o narrador-personaje eventual-como si le fueran accesibles, la paralepsis estilística consistirá en la incorporación en el discurso de unos rasgos estilísticos inaccesibles al emisor en el momento de la emisión -sea tal emisor el narrador, o sea un personaje de quien el narrador cita, como si fuera auténtico, discurso que (en todo o en parte) no ha sido emitido por ese 
personaje. Hacia el comienzo de "El infierno", el narrador atribuye a Risso un texto mental impregnado de rasgos estilísticos del discurso del propio narrador inaccesibles a Risso en el momento en que lo enuncia. El momento es importante para nuestra opción de lectura, porque en él se está fraguando intensamente el acercamiento psíquico del narrador al personaje, acercamiento al cual así se contribuye como en sentido inverso: desde el personaje al narrador. ¿Qué solución encontraremos a esta clase de paralepsis para poder efectuar su naturalización? En el caso de nuestro texto, el cuento puede fácilmente darnos la ilusión de que no existe la paralepsis estilística; ésta es su principal solución de la misma.

(D) La focalización como aspecto de la información dada. Focalización externa, o interna; e interna inmediata, o mediata. Focalización directa (u "objeto"), o restringida ( $($ "sujeto"); y focalización sujeto con objeto interno, o con objeto externo. También la focalización resulta, en este marco, un aspecto posible de la transmisión de información - y todas las formas indicadas en el subtítulo tendrán importancia semiósica en nuestro análisis ulterior. El criterio básico que determina el hecho y las clases de la focalización es la expresión/no expresión de la perceptibilidad del objeto del que el narrador informa - cuando tal objeto es perceptible por medios externos o internos: sea por los sentidos corporales externos de un sujeto perceptor, sea por la mente cuando se trata de un fenómeno mental. Entre los fenómenos mentales deben incluirse sentimientos, voliciones, recuerdos, incluso ideas abstractas en cuanto componentes de un acto de percepción - aunque no en lo que concierne a sus objetos mismos - si son presentados corıo pensamientos de algún actor de la historia o de algún participante del discurso - como el propio narrador o su destinatario, aunque éste no forme parte de la historia. Con respecto, pues, a la pareja dual "externa" Pinterna" que se ha empleado para denominar las clases de focalización, no sigo el uso que han venido adoptando varios narratólogos, a partir quizás de las sugerencias de Mieke Bal (Edminston 1989: 729), sino mantengo el sentido más antiguo, al parecer, en narratología, cuyo criterio es la clase de perceptibilidad de los fenómenos, como se halla, entre otros, en Booth (1983/61: 163 ss.), Uspenski (1973: 83-86), Lanser (1981: 207-211), Fowler (1986: 134-135).

Así, hablando el narrador en forma tal que la perceptibilidad del objeto quede expresa o tácita en su discurso, hace focalización externa cuando informa sobre objetos perceptibles por los sentidos corporales externos del sujeto perceptor operando con su capacidad convencionalmente normal ("Juan iba caminando"); focalización interna inmediata cuando informa sobre fenómenos convencionalmente perceptibles sólo por la mente del sujeto productor de tales fenómenos ("Juan estaba contento"; "Yo estoy contento") si los percibe también el narrador; y focalización interna mediata si el narrador no los percibe pero informa sobre ellos por inferencia de los signos externos perceptibles, o de testimonios del propio sujeto productor o de terceros. La focalización puede ser 
directa (como en los ejemplos anteriores), i.e., realizarse directamente por el narrador sin intermediación de ningún otro sujeto, y en tal caso podemos hablar de focalización-objeto (adoptando la sugerencia de Vitoux 1982: 359-360). O bien, puede estar restringida al campo de percepción de un sujeto diferente del narrador, y en tal caso a la focalización-objeto se agrega (adoptando otra vez la terminología de Vitoux 1982: 359-360) una focalización-sujeto ("Juan vioque ... Juan pensó [creyó, sintió, recordó, etc.] que ...”) con objeto externo (“Juan vio que María venía a su encuentro"), o con objeto interno ("Juan recordó que en el encuentro anterior con María no había sentido la timidez que ahora lo embargaba"), y en ambos casos la focalización-sujeto puede coexistir con una (otra) directa focalización-objeto interna (“... y Juan se sintió contento / pero Juan se equivocaba") que opera como retroalimentación informacional del narrador acerca de la percepción sobre la cual ha informado. Todas estas precisiones son relevantes en la red semiósica del texto de Onetti, según la lectura practicada.

(E) El estilo del discurso del narrador como medio expresivo de su empatía con el personaje. Es frecuente encontrar la idea de que la focalización interna contribuye a la sugerencia de la empatía del narrador con el personaje y, por tanto, a la simpatía del lector hacia el último; así en Booth (1983/1961: 246, 323, Lanser (1981: 206-208), etc. En realidad, de aceptarse las distinciones y precisiones anteriores sobre la focalización y la información, habría tal vez que considerar aquí como el factor fundamental y genérico de tal efecto semántico, no la focalización sino la información $\mathrm{N}=\mathrm{P}, \mathrm{y}$ la focalización interna como necesario- factor subordinado y especifico (necesario elemento de aquél). También, incluso, está bien reconocido que el estilo indirecto libre (al cual me he de referir en el apartado siguiente) puede contribuir al mismo efecto (por ejemplo, Genette, 1972, 192, Lanser 1981, 191) -y que éste a menudo se pone, precisamente, al servicio funcional de la focalización interna (tanto que Fowler llega a definirlo como un procedimiento a tal servicio; $(1986,138)$. Pero no es frecuente encontrar la observación de que la empatía del narrador queda notablemente intensificada en esas coyunturas narrativas si también su estilo se adecúa eficazmente ( $y$ seriamente, claro está: sin ironias, flaubertianas o de otra clase) a la expresión del sentir del personaje. Esta idea debe agregarse a la homóloga y bien sabida de que el estilo del narrador puede también usarse con gran eficacia para la expresión del distanciamiento afectivo del personaje por parte del mismo narrador, y -más ampliamente- al reconocimiento de la contribución semiósica del estilo a la expresión -como ha subrayado Susan Lanser (1981, 216-217). Advertido esto, llega a nuestro encuentro, funcionalmente redimido y recuperado para la narratología, lo mejor de la (ya) vieja estilística y del New Criticism de los primeros dos tercios del siglo, y de toda la retórica tradicional que ellos potencialmente contenían, para ponerse a nuestra disposición comoinstrumento de análisis notablemente útil. Ciertamente tienen notoria utilidad para la explicación de la lectura practicada de "El 
infierno".

(F) El estilo indirecto libre como imposición lingüística y diegética, y el estilo indirecto libre como "hipótesis". En el apartado anterior me he referido a un efecto semántico importante del estilo indirecto libre, componente destacado de la red semiósica; me he de referir aquí a una situación textual del procedimiento que tiene relevancia semiósica en dicha red. Shlomith Rimmon-Kenan sugestivamente considera que el estilo indirecto libre es una "hipótesis" que frecuentemente hay que aplicar a un texto (1983: 113). Yo reservaré la denominación de "hipótesis" para el estilo indirecto libre cuando éste se da en una coyuntura específica. Me refiero a la instancia en que las características lingüísticas y diegéticas del texto no imponen la postulación del estilo indirecto libre, perolo permiten, $\mathrm{y}$ (sobre todo) su empleo resulta aceptableo recomendable dentro de cierta lectura que el texto va sugiriendo. Propongo que un indicio casi siempre seguro de la existencia del estilo indirecto libre en un segmento dado es la posibilidad de transformar ese segmento en estilo indirecto subordinado bajo la regencia de un verbo "dicendi" o declarativo sugerido por el contexto inmediatamente precedente. (Si, por ejemplo, el segmento en cuestión es el ejemplo genettiano "Marcel fue a ver a su madre: Tenía quc casarse con Albertine", un verbo declarativo sugerido podría ser "decir": "Marcel fue a ver a su madre y le dijo que tenía que casarse con Albertine".) Ahora bien, hay instancias en que el verbo declarativo no está sugerido ni explícita ni implícitamente por el contexto, porque no se necesita la postulación del estilo indirecto libre para que la histoira o (más ampliamente) la diégesis tenga coherencia narrativa; sin embargo, la diégesis admitiría la lectura resultante, y la gramática del fragmento dado aceptaría la transformación requerida. En tales casos, pues, la aplicación de la hipótesis del estilo indirecto libre depende de su adecuación a la lectura que el texto le ha venido sugiriendo al receptor. Esta "hipótesis" ha tenido una relevancia destacable en la red semiósica de nuestra lectura de "El infierno tan temido".

\section{CONCLUSIÓN: ¿UNA DES-DESCONSTRUCCIÓN?}

Quedan así completas, a mi entender, las bases narratológicas para la lectura que compartíamos - que podía compartir (en todo o en parte) el presente lector real de este trabajo con la comunidad de lectores del cuento que se sienten de alguna manera identificados con el lector implícito de la lectura practicada. Volvamos, a manera de conclusión interina, al centro de esa lectura, desde el cual partimos: allí encontrábamos el núcleo de la red semiósica que estas bases narratológicas conceptualizan y articulan, la homodiégesis del narrador. La homodiégesis del narrador supone en este casola unicidad del mismo, negándose por ende la sofisticada pluralidad de narradores que la crítica ha señalado en El astillero y otras obras de Onetti (Cosse 1989, 41-43). Corriendo, pues, conscientemente el riesgo de ingenuidad, esta lectura ni siquiera vería signos 
determinantes de una diferencia óntica necesaria entre los narradores de dos clases de sectores narrativos en los que tal diferencia podría fácilmente postularse. ${ }^{8}$ Una clase, en la que domina el relato escénico, o al menos singular, la construcción de la oración es predominantemente paratácita, y no hay homodiégesis explícita ni fuertemente inferible; otra, en la que domina el relato panorámico, la construcción de la oración es predominantemente hipotáctica, y la homodiégesis es explícita ofuertemente inferible. (No se me oculta que si la empresa resulta exitosa podría aconsejar el cuestionamiento, conforme a los mismo criterios, de la aceptada pluralidad de narradores en otros textos de Onetti, peroesto no forma parte del trabajo presente ni del que lo complementa).

¿Supone esto una especie de desconstrucción que siguiera un camino inverso al habitual? Parecería que sí, para el lector a quien resultara obvia e "impuesta" por el texto tal diversidad de narradores - y en la medida de tal obviedad e imposición. Dicho de otro modo, en la medida en que el texto mismo generara su propia desconstrucción -en este caso, para la figura del narrador-esta lectura desconstruiría tal proceso: desconstruiría tal desconstrucción. Se actualiza así un principo operante aquí desde la primera frase del trabajo, la supremacía de la lectura: cierta lectura del tex to es aquí el hecho básico, el resto es el esfuerzo de explicarla. El principio pertenece ciertamente a la postmodernidad en teoría y crítica literarias, pero hace más de quince años decía Culler que esto ya se inaugura en el estructuralismo (Culler 1975), y no faltan quienes ven en el New Criticism un "emphasis on the importance of the reader's response" (Gardner 1982: 7; ver también 23). Y tal vez, tal vez ... se trata de la misma tarea sempiterna de explicarse y crear el mundo mediante la (co)producción de la ficción. "But," como replicaba Northrop Frye ante una observación análoga y la implicación consiguiente de repetir lo consabido, "one hopes for some growth in lucidity" (1971,9); lo esperamos del modo como (en la postmodernidad) tratamos de encarar la tarea si agregamos la luz de nuestra lámpara, por modesta que sea, a la que nos aporta la suma de las luces que nos han precedido. Tal ha sido mi empeño en este trabajo (y lo es en el trabajo de comentario textual que lo complementa y continúa): compartir una lectura y una explicación de la misma que procuran prolongar/unirse a las tareas del autor/co-lector del mundo - del lector/co-autor del mundo.

\footnotetext{
- Dentro de esta corriente también cabría, quizás, la consideración de varios narradores homodiegéticos y varios narradores heterodiegéticos. En la lectura que sigo, sin embargo, se tiende por principio a "no multiplicar los entes" si el texto no lo exige con signos indudables $\longrightarrow$ al menos, con signos claramente plausibles dentro de cierta lectura. En efecto, parte de la "naturalización" (nota 7) del discurso, en nuestra lectura, consiste en atribuirlo a un solo emisor a no ser que existan tales signos.

- Ambas clases tienen también otros rasgos que se indican en el aludido trabajo de comentario textual -Renart (1992): sección 3.3-; se examinan en ese lugar las semejanzas y signos de coherencia entre ambas clases que permiten considerarlas integrantes del discurso del mismo sujeto.
} 


\section{OBRAS CITADAS}

Abrams, M. H., A Glossary of Literary Terms, $5^{\mathrm{a}}$ edición New York: Holt, 1988. Ainsa, Fernando, Las trampas de Onetti. Montevideo: Alfa, 1970.

Benedetti, Mario, "Juan Carlos Onetti y la aventura del hombre", en El ejercicio del criterio, 131-153. México: Nueva Imagen, 1981, publicación original 1965.

Bonth, W., The Rhetoric of Fiction. Chicago: University of Chicago Press,1983; publicación original 1961.

Cosse, R., Fisión literaria: Narrativa y proceso social. Montevideo: Monte Sexto, 1989.

Culler, Jonathan, Structuralist Poetics: Structuralism. Linguistics and the Study of Literature. London: Routledge and Kegan Paul, 1975.

Eco, Umberto, La estructura ausente: Introducción a la semiótica, Barcelona: Lumen, 1972.

A Theory of Semiotics. Bloomington: Indiana University Press, 1979 Midland Book edition; publicación original 1976.

Edminston, W. F., "Focalization and the First-Person Narrator: A Revision of the Theory". Poetics Today 10, 4 (Winter, 1989), 729-744.

Elliot, R. C., The Literary Persona. Chicago: University of Chicago Press, 1982.

Fowler, R., Linguistic Criticism. Oxford y Nueva York: Oxford University Press, 1986.

A Dictionary of Modern Critical Terms. London: Routledge, 1987.

Frye, N., The Critical Path: An Essay on the Social Context of Literary Criticism. Bloomington: University of Indiana Press, 1971.

Gardner, Helen, In Defence of the Imagination. Cambridge: Harvard University Press, 1982.

Genette, Gérard, "Discours du récit: Essai de méthode", en Figures III: 65-273. Paris: Seuil, 1972.

Nouveau discours du récit. Paris: Seuil, 1983.

Lanser, Susan S., The Narrative Act: Point of View in Fiction. Princeton: Princeton University Press, 1981.

Nelles, W., "Getting Focalization into Focus". Poetics Today 11, 2 (Summer, 1990), 365-382.

Mercier, L., "Juan Carlos Onetti en busca del infierno" en Homenaje a Juan Carlos Onetti, 225-234. Ed. Helmy F. Giacoman. Madrid: Anaya, 1974.

Ocampo, Aurora M., "La mujer en El infierno tan temido". Texto Crítico 6 (juliodiciembre, 1980), 223-234.

Onetti, Juan Carlos, Obras completas. Prólogo de E. Rodríguez Monegal. Madrid: Aguilar, 1970.

Prince, G., Narratology: The Form and Function of Narrative. Berlin: Mouton, 1982. 
A Dictionary of Narratology. Lincoln: University of Nebraska Press, 1987.

Reis, C. y Ana C. Lopes, Diccionário de narratologia. Coimbra: Livraria Almedina, 1987.

Renart, J. Guillermo, El Cristo de Velázquez de Unamuno: Estructura, estilo, sentido. Toronto: University of Toronto Press, 1982.

"Problemas semióticos de la narrativa ideológica de personaje: Tulio Montalbán y Julio Macedo de Unamuno" en Revista Canadiense de Estudios Hispánicos 11, 2 (invierno, 1987), 377-402.

"Hacia el uso de la ciencia de la literatura por las ciencias sociales: Demostración mediante textos de la poesía folklórica quechua". Revista Canadiense de Estudios Hispánicos 13, 3 (primavera, 1989), 383-428.

Rimmon-Kenan, Shlomith, Narrative Fiction: Contcmporary Poetics. London y Nueva York: Methuen, 1983.

Rodríguez Monegal, Emir, "La fortuna de Onetti" en Literatura uruguaya del medio siglo . Montevideo: Alfa, 1965, 221-260.

Risco, A., Literatura y figuración. Madrid: Gredos, 1982.

Rodríguez Alonso, Pilar, "Un aspecto del tiempo en los cuentos de Juan Carlos Onetti: "Análisis de El infierno tan temido" en Lexis 11, 2 (1987), 183-208.

Stanzel, F.K., A Theory of Narrative. Cambridge: Cambridge University Press, 1986; publicación original, $1^{\underline{a}}$ ed., 1979.

Uspenski, Boris, A Poetics of Composition: The Structure of the Artistic Text and Typology of a Compositional Form. Berkeley: University of California Press, 1973; publicación original 1970.

Vitoux, P., "Le jeu de la focalisation". Poétique 51 (septembre, 1982), 360-368. 
